the structures can be solved using X-ray crystallography. The compounds identified by Schmid et al. should also inform our understanding of signalling through G-proteincoupled receptors in general. Given that such receptors are implicated in many diseases, this could pave the way for the development of numerous drugs that have minimal side effects.

Susruta Majumdar is in the Department of Neurology, Memorial Sloan Kettering Cancer Center, New York, New York 10065, USA. Lakshmi A. Devi is in the Department of Pharmacological Sciences, Icahn School of Medicine at Mount Sinai, New York,

New York 10029, USA.

e-mails:majumdas@mskcc.org;

lakshmi.devi@mssm.edu

1. Schmid, C. L. et al. Cell 171, 1165-1175 (2017).

2. Institute of Medicine. Relieving Pain in America (Natl Acad. Press, 2011).

3. Pasternak, G. W. \& Pan, Y.-X. Pharmacol. Rev. 65, 1257-1317 (2013)

4. Grinnell, S. G. et al. Synapse 70, 395-407 (2016).

5. Ananthan, S. AAPS J. 8, E118-E125 (2006).

6. Eans, S. O. et al. J. Med. Chem. 58, 4905-4917 (2015).

7. Spahn, V. etal. Science 355, 966-969 (2017).

8. Fujita, W., Gomes, I. \& Devi, L. A. Br. J. Pharmacol. 172, 375-387 (2015).

9. Burford, N. T. et al. Proc. Natl Acad. Sci. USA 110,
10830-10835 (2013)

10. Rankovic, Z., Brust, T. F. \& Bohn, L. M. Bioorg. Med. Chem. Lett. 26, 241-250 (2016).

11.Bohn, L. M. et al. Science 286, 2495-2498 (1999).

12.Bu, H., Liu, X., Tian, X., Yang, H. \& Gao, F. Int. J. Neurosci. 125, 56-65 (2015).

13.Li, Y. et al. Int. J. Mol. Sci. 10, 954-963 (2009).

14. Raehal, K. M., Walker, J. K. \& Bohn, L. M. J. Pharmacol. Exp. Ther. 314, 1195-1201 (2005).

15. Harding, W. W. et al. J. Med. Chem. 48, 4765-4771 (2005).

16.DeWire, S. M. et al. J. Pharmacol. Exp. Ther. $\mathbf{3 4 4}$ 708-717 (2013).

17. Manglik, A. etal. Nature 537, 185-190 (2016).

18.Kruegel, A. C. et al. J. Am. Chem. Soc. 138, 6754-6764 (2016).

19.Váradi, A. et al. J. Med. Chem. 59, 8381-8397 (2016).

20.Altarifi, A. A. et al. J. Psychopharmacol. 31, 730-739 (2017).

\section{Homing in on a key factor of climate change}

\section{The sensitivity of Earth's climate to atmospheric carbon dioxide levels is a big unknown in predicting future global warming. A compelling analysis suggests that we can rule out high estimates of this sensitivity. SEE LETTER P.319}

uncertain. It has also become a focus for those who doubt the robustness of climate science, who use it to suggest that the field as a whole is intrinsically unreliable. Despite the huge progress in our understanding of climate science over the past 40 years, the Intergovernmental

Panel on Climate Change (IPCC) concluded $^{1}$ in 2013 that there is a $66 \%$ likelihood of ECS being between $1.5^{\circ} \mathrm{C}$ and $4.5^{\circ} \mathrm{C}$ (Fig. 1). This is little different from the range first postulated ${ }^{6}$ by the meteorologist Jule Charney and colleagues in 1979.

Cox and co-workers' estimate is exciting because it develops an underexplored line of evidence: the natural variability of global temperature. The authors also provide the first convincing evidence that we are not living in a world in which ECS is greater than the range of values thought likely by the IPCC. This is important, because estimates of ECS based on the historical temperature record have largely been unable to exclude high values that would invariably result in world-devastating warming of $4^{\circ} \mathrm{C}$ or more by 2100 .

Past research that seemingly constrained the top end of ECS estimates to lower values often excluded major uncertainties, or worked from a previous estimate of ECS that was skewed towards low values. The published ranges therefore depended on the researchers' assumptions about ECS, rather than the evidence. By contrast, Cox et al. started from climate-model values that are at the upper end of the IPCC range, and used evidence to effectively rule out catastrophically high values: they estimate that there is a $66 \%$ likelihood of ECS being between $2.2^{\circ} \mathrm{C}$ and $3.4^{\circ} \mathrm{C}$, with less than a $1 \%$ chance of it being greater than $4.5^{\circ} \mathrm{C}$ (Fig. 1).

The idea underpinning this work

Figure 1 | Estimates of equilibrium climate sensitivity (ECS). ECS quantifies the increase in Earth's average surface temperature that would occur if atmospheric carbon dioxide levels were doubled and the climate system was allowed to reach an equilibrium state. Estimates of ECS vary depending on the evidence used (such as records of Earth's energy budget ${ }^{9}$ and analyses ${ }^{4}$ of present climate conditions produced by models). The estimate ${ }^{1}$ from the Intergovernmental Panel on Climate Change (IPCC) published in 2013 is based on several lines of evidence. Cox et al. ${ }^{5}$ now report estimates based on an analysis of surfacetemperature variation predicted by climate models. Their analysis rules out high estimates of ECS. Bars depict ranges for which there is a $66 \%$ likelihood of the value being correct; for the top two bars, these ranges have been inferred from the data in references 4 and 9 . Best estimates of ECS for each range, if available, are indicated by a blue line. is so enviably simple that it will make climate scientists ask, "Why didn't I think of that?" The authors examined the variability of surface temperature in terms of its variance and autocorrelation - the 'memory' of a previous year's surface temperature that is retained in measurements taken the following year. They then developed a theory-derived metric of surfacetemperature variability and evaluated this metric in historical simulations 
from 22 computational models of the Earth system, ultimately finding that it is a good predictor of the inherent ECS of each of the models.

Cox et al. then used the relationship between the metric and the ECS found in the models as a constraint on ECS in the real world. Their analysis revealed that only climate models that produce relatively small values of ECS match the variability seen in the historical temperature record. It turns out that, in general, climate models have considerable memory in their climate systems, so if one year is abnormally hot, for example, then the next year is likely also to be hot. The historical temperature record, however, does not seem to have as much system memory as most models. This means that some models have both autocorrelations and ECS values that are too high.

These new findings must be interpreted carefully. ECS is arguably the main factor that governs uncertainty in projected temperatures, but is not the only factor. For example, Earth-system feedbacks such as the effects of permafrost melting are expected to increase warming. Climate models often exclude these feedbacks, reducing the projected warming. In models that have an ECS that is too high, such exclusions could potentially compensate for the effects of the inflated ECS value.

It is also crucial to examine other lines of evidence when assessing ECS. The best estimates of ECS that have been made by analysing Earth's energy budget (the balance of the energy received by Earth from the Sun and the energy radiated back to space) are relatively low, at around $2{ }^{\circ} \mathrm{C}$ (ref. 7). But recent work ${ }^{8}$ is helping us to understand that ECS values inferred from energy-budget changes over the past century are probably low, and shows that a higher value is more applicable when projecting future change. Applying such a correction to the original estimates ${ }^{9}$ brings their values very much in line with Cox and co-workers' estimate (Fig. 1).

By contrast, analyses ${ }^{3}$ of present climate conditions (particularly cloud properties)

"The idea
underpinning
this work is so
enviably simple
that it will
make climate
scientists ask,
"Why didn't I
think of that?"
produced by models show that the models that best represent today's climate have ECS values greater than $3^{\circ} \mathrm{C}$. Indeed, one of the most recent of these analyses ${ }^{4}$ showed that models with an ECS of around $4{ }^{\circ} \mathrm{C}$ best captured today's climate across nine emergent constraints (Fig. 1). In my view, Cox and colleagues' estimate and the estimates produced by analysing the historical energy budget carry the most weight, because they are based on simpler physical theories of climate forcing and response, and do not directly require the use of a climate model that correctly represents cloud. To resolve which estimates are most accurate, more research is needed to compare the different lines of evidence and to improve the representation of clouds in models.

I hope that a much more refined estimate of ECS can be made from the different lines of evidence by the time the next IPCC assessment is published in 2021. If the upper limit of ECS can truly be constrained to a lower value than is currently expected, then the risk of very high surface-temperature changes occurring in the future will decrease. This, in turn, would improve the chances of keeping the temperature increase well below $2{ }^{\circ} \mathrm{C}$ above pre-industrial levels, the target of the Paris Agreement under the United Nations Framework Convention on Climate Change. So, rather than be jealous, I should thank Cox and colleagues for helping me to sleep a little easier in my bed at night. $\square$

Piers Forster is at the School of Earth and Environment, University of Leeds, Leeds LS2 9JT, UK.

e-mail:p.m.forster@leeds.ac.uk

1. Stocker, T. F. et al. (eds) Climate Change 2013: The Physical Science Basis. Contribution of Working Group I to the Fifth Assessment Report of the Intergovernmental Panel on Climate Change (Cambridge Univ. Press, 2013).

2. Weitzman, M. L. Rev. Environ. Econ. Policy 5, 275-292 (2011).

3. Knutti, R., Rugenstein, M. A. A. \& Hegerl, G. C. Nature Geosci. 10, 727-736 (2017).

4. Brown, P. T. \& Caldeira, K. Nature 552, 45-50 (2017).

5. Cox, P. M., Huntingford, C. \& Williamson, M. S. Nature 553, 319-322 (2017).

6. Charney, J. G. et al. Carbon Dioxide and Climate: A Scientific Assessment (Natl Acad. Sci., 1979).

7. Forster, P. M. Annu. Rev. Earth Planet. Sci. 44, 85-106 (2016).

8. Ceppi, P. \& Gregory, J. M. Proc. Natl Acad. Sci. USA 114, 13126-13131 (2017).

9. Armour, K. C. Nature Clim. Change 7, 331-335 (2017).

a wealth of events in which translation is initiated at alternative start codons ${ }^{3}$ (triplets of nucleotides other than the triplets at which translation is normally assumed to initiate), and read-through events ${ }^{4}$ in which translation continues beyond the stop codon (the nucleotide triplet at the end of the ORF). Not only do these two types of event increase the overall diversity of proteoforms (molecular forms of proteins produced from genes) ${ }^{5}$, but they have also emerged as regulatory mechanisms for hundreds of genes in eukaryotic genomes. Other regulatory mechanisms for translation are also known, including ribosome stalling, in which obstacles impede ribosome movement along mRNAs.

Yordanova et al. now propose another evolutionarily conserved mechanism for translational control. They suggest that sporadic stop-codon read-throughs can lead to the formation of ribosome queues at downstream stalling sites, such that the queue length is proportional to the number of protein molecules that have been synthesized. The authors define the region between the end of the main ORF and the next in-frame stop codon (that is, the next nucleotide triplet that would be recognized as a stop codon by a eukaryotes - organisms such as fungi, plants a stretch of nucleotides that contains an open reading frame (ORF), which encodes a single protein containing more than 100 aminoacid residues. But over the past decade, the advent of technologies such as ribosome profiling ${ }^{2}$ has revealed that a more-diverse range of ORF sequences can, in fact, be translated. For example, numerous small upstream ORFs (uORFs) have been identified whose translation might regulate expression of the main ORF.

Ribosome profiling has also revealed 